\title{
Espaço Infantil em eventos da Sociedade Brasileira de Computação: uma necessidade ou não?
}

\author{
Leticia Santos Machado', Silvia Amélia Bim², Karen da Silva Figueiredo Medeiros \\ Ribeiro $^{3}$, Luciana Bolan Frigo ${ }^{4}$, Cristiano Maciel $^{3}$
}

${ }^{1}$ Programa de Pós-Graduação em Computação - UFPA, Belém, Pará, Brasil

${ }^{2}$ Departamento Acadêmico de Informática - UTFPR, Curitiba, Paraná, Brasil

${ }^{3}$ Instituto de Computação \& Instituto de Educação - Universidade Federal do Mato Grosso (UFMT), Cuiabá, Mato Grosso, Brasil

${ }^{4}$ Departamento de Computação - UFSC, Araranguá, Santa Catarina, Brasil

leticia.smachado@gmail.com, sabim@utfpr.edu.br, karen@ic.ufmt.br,
Luciana.frigo@ufsc.br, cmaciel@ufmt.br

\begin{abstract}
One of the rights sought by the countless initiatives for gender equality is that of responsible parenthood. In this context, among the demands of parents who work in scientific research there is the need to take part in conferences. This article presents data from a survey carried out by the Digital Girls Program (Programa Meninas Digitais) on the need to offer a childcare service that can accommodate the children of parents who are attending scientific conferences organized and supported by the Brazilian Computer Society.
\end{abstract}

Resumo. Um dos direitos almejados pelas inúmeras iniciativas para a equidade de gênero é o da parentalidade responsável. Neste contexto, dentre as demandas de mães e pais que atuam na pesquisa científica está a participação em eventos com apoio para o cuidado de crianças. Neste artigo, são apresentados dados de um levantamento realizado pelo Programa Meninas Digitais sobre a necessidade de oferecer um espaço infantil que possa acolher as crianças de mães, pais e responsáveis que estejam participando dos eventos científicos organizados e apoiados pela Sociedade Brasileira de Computação.

\section{Introdução}

$\mathrm{Na}$ área científica, o relatório "Gender in the Global Research Landscape”, publicado pela Elsevier (2017), apontou que o número de cientistas de gênero feminino no Brasil alcançou $47 \%$ do total de pessoas pesquisadoras. Por outro lado, os dados do Conselho Nacional de Desenvolvimento Científico e Tecnológico - CNPq (2017) indicam que o número de mulheres nas Ciências no Brasil diminui à medida que a carreira científica avança, ou seja, em posições acadêmicas consideradas mais altas e prestigiadas há menos mulheres. Um exemplo é o número de bolsistas de produtividade $\mathrm{CNPq}$, uma marca de excelência na carreira científica no Brasil, que registrou apenas $36 \%$ das bolsas de produtividade às pesquisadoras mulheres em 2017 [Machado et al. 2019].

A ausência de dados quantitativos dificulta a compreensão sobre o cenário de mulheres e mães atuantes na área acadêmica no contexto brasileiro, em qualquer estágio 
(graduação, mestrado, doutorado, pós-doutorado, professoras e pesquisadoras). Diante desta carência, o grupo Parent in Science ${ }^{\prime}$, fundado em 2017, foi criado com o objetivo principal de investigar o impacto da parentalidade na carreira científica no Brasil. Utilizando surveys on-line, o grupo conseguiu coletar dados de mais de 2000 pessoas pesquisadoras brasileiras, incluindo as de gênero feminino e as de gênero masculino responsáveis por crianças. A maioria das cientistas entrevistadas eram mães (78\%) e o número de filhas e filhos estava distribuído em uma criança $(56,2 \%)$, duas crianças $(38,5 \%)$ e três ou mais crianças $(5,14 \%)$. Sobre a distribuição nas áreas de conhecimento, os resultados obtidos apresentaram que as pesquisadoras mães da área de STEM (Science, Technology, Engineering and Mathematics ${ }^{2}$ ) representavam $20 \%$ do total. A análise dos dados também revelou que pesquisadoras de gênero feminino sofrem um impacto negativo imediato nas suas produtividades após tornarem-se mães, devido à queda no número de publicações durante os quatro primeiros anos após o nascimento de filhas ou filhos. Por sua vez, Machado et al. (2019) discutem a necessidade de ações e políticas públicas para suportar mães e pais que realizam pesquisas no Brasil.

As ações do projeto Parent in Science no Brasil (2020) incluem a realização de dois simpósios nacionais para discutir a temática: "Maternidade e Ciência" (2018) e "Maternidade e Ciência: Avanços nas Instituições de pesquisa brasileiras" (2019). A edição prevista para 2020 propõe ampliar o debate com o título "III Simpósio Brasileiro sobre Maternidade e Ciência: As interfaces entre Universidade e Sociedade". Além disso, já foram resultados das ações deste grupo: a flexibilização sobre o critério de elegibilidade e avalição nos editais de fomento, que estende o período de análise do currículo em um ano por licença maternidade; reconhecimento da informação nascimento e de adoção de filhas e filhos no currículo Lattes ${ }^{3}$; e a oferta de serviço de recreação infantil em eventos científicos de diversas áreas no Brasil, como na Reunião Anual da Sociedade Brasileira de Química e no Congresso Brasileiro de Toxicologia.

Embora desde 2007 a Sociedade Brasileira de Computação (SBC) discuta questões relacionadas à representatividade de mulheres na Computação por meio do evento Women in Information Technology (WIT) e desde 2011 realize ações através de dezenas de projetos parceiros que fazem parte do Programa Meninas Digitais ${ }^{4}$ [Maciel et al. 2018], ainda não tem-se percebido discussões relacionadas à parentalidade responsável para a comunidade científica de Computação.

Face a falta de iniciativas neste campo e considerando a possibilidade de oferta de serviços de recreação infantil em eventos científicos, este artigo objetiva analisar os dados obtidos em uma pesquisa com pessoas associadas à SBC sobre a real necessidade de oferecer um espaço infantil em eventos. Popularmente conhecido como "espaço kids", esse tipo de ambiente visa acolher crianças de mães e pais participantes dos eventos científicos organizados e apoiados por esta instituição.

Sob o ponto de vista metodológico, este artigo descreve uma pesquisa de opinião exploratória, sendo a coleta de dados realizadas via questionário on-line. O questionário foi composto com questões sobre a expectativa e necessidade, tanto de pessoas que nunca tiveram a experiência de participar de um evento científico com espaço infantil, quanto

\footnotetext{
${ }^{1}$ https://www.parentinscience.com

${ }^{2}$ Ciência, Tecnologia, Engenharia e Matemática

${ }^{3}$ Demanda ainda não implementada na plataforma.

${ }^{4} \mathrm{http}: / /$ meninas.sbc.org.br/
} 
de pessoas que já vivenciaram experiências semelhantes em eventos organizados por outras entidades científicas. Os achados da pesquisa são analisados de forma qualitativa, sendo apresentados sob a forma de texto, tabelas e gráficos.

\section{Eventos científicos e Espaço Infantil}

Neste artigo, considera que um espaço infantil caracteriza-se, popularmente, como um lugar dedicado ao acolhimento de crianças com brinquedos, atividades, jogos etc., oferecido por profissionais capacitados que garantam a segurança e cuidados dessas crianças enquanto estiverem sob custódia deste espaço.

Com relação às iniciativas das diferentes áreas de conhecimento no âmbito brasileiro, percebe-se que a maioria destas tratam de iniciativas recentes e são impulsionadas pela ação de inclusão realizada nos eventos promovidos pelo Parent in Science em 2018 e 2019. A Tabela 1 apresenta alguns exemplos de eventos extraídos de forma livre das redes sociais do Parent in Science que planejam oferecer ou já ofereceram um espaço infantil durante suas atividades científicas.

Tabela 1. Eventos científicos brasileiros com espaço infantil

\begin{tabular}{|c|c|c|c|}
\hline Área & Filiação & Evento & Ano \\
\hline Psicologia & MG & Jornada COGCOM & 2020 \\
\hline Biologia & AM & AquaCiência & 2020 \\
\hline Biomedicina & RS & Congresso Brasileiro de Toxicologia & 2020 \\
\hline Química & AL & Reunião Anual da Sociedade Brasileira de Química & 2020 \\
\hline Multidisciplinar & RS & Simpósio Brasileiro sobre Maternidade e Ciência & $2019 / 2018$ \\
\hline
\end{tabular}

Ainda, no contexto brasileiro, o coletivo de mulheres Observatório Cajuína divulgou, em agosto de 2019, uma carta aberta à comunidade com recomendações para inclusão de mães em eventos científicos diversos'. A carta vem sendo reproduzida por outras instituições, como o Conselho Regional de Psicologia da $9^{\text {a }}$ Região - Goiás ${ }^{8}$.

O $9^{\circ}$ Fórum da Internet no Brasil (2019), promovido pelo Comitê Gestor da Internet no Brasil (CGI.br), contou com um painel para discutir sobre uma maior participação das mulheres na área de TIC. A síntese do relatório do painel [Maciel et al. 2019] traz questões que emergiram do fórum, pelas painelistas e das perguntas do público. Da plateia, surgiu a manifestação da "necessidade de inserção de crianças nos projetos", sendo consenso entre as pessoas participantes ser "necessário considerar 'a família' neste processo". Como pontos a aprofundar, o relatório aponta a necessidade da existência "de oficinas para crianças participarem, especialmente em conjunto com pais, mães e responsáveis, para que elas vivenciem essa realidade" e "de 'espaços kids' em eventos para que as mães possam, de fato, participar dos eventos".

No cenário internacional, a CHI (Conference on Human Factors in Computing Systems) oferece desde $2018^{\circ}$ o serviço de Childcare \& Nursing Room para crianças de 6 meses a 12 anos e a opção de Child Pass para crianças de 0 a 18 anos que queiram

\footnotetext{
${ }^{5}$ bit.ly/jeckids

${ }^{6}$ bit.ly/2Vq4LHd

${ }^{7}$ https://observatoriocajuin.wixsite.com/cajuina/post/carta-aberta-à-comunidade-científica-como-incluirmães-nos-congressos

${ }^{8} \mathrm{http}$ //www.crp09.org.br/portal/noticia/2440-crp-09-divulga-carta-aberta-a-comunidade-cientificacomo-incluir-maes-nos-congressos

${ }^{9} \mathrm{https}$ ://chi2018.acm.org/attending/child-care-nursing-room/
} 
acompanhar os responsáveis na conferência. Todos os serviços têm custos para as pessoas participantes, entretanto alguns são subsidiados pela organização do evento e suas entidades patrocinadoras.

A necessidade de serviços de apoio em eventos científicos para participantes com crianças também foi apresentada por um grupo de mães cientistas da área de Neurobiologia e Fisiologia da Universidade da Califórnia [Calisi et al. 2018]. Então, um levantamento feito pela Science Career analisou 34 conferências científicas realizadas nos EUA, com mais de mil participantes, para verificar se as recomendações feitas por Rebecca Calisi e o seu Grupo de Trabalho de Mães Científicas estavam sendo respeitadas [Langin 2018]. Os resultados indicaram que 94\% das conferências analisadas ofereceram uma sala de amamentação e $68 \%$ ofereceram algum tipo de assistência para crianças.

Embora os números pareçam ser positivos, a maioria dos serviços são pagos, o que dificulta o uso deles por estudantes de pós-graduação, por exemplo. Além disto, a simples oferta dos serviços não garante um ambiente acolhedor para participantes com crianças. É necessária também a definição de um código de conduta para todas as pessoas que participam do evento, buscando evitar situações constrangedoras ${ }^{10}$, e a indicação de serviços complementares.

Até onde vai o conhecimento das autoras e do autor deste trabalho, esta é a primeira pesquisa sobre a demanda de espaço infantil em eventos científicos da área de Computação no Brasil, fato pelo qual não são cotejados outros referenciais sobre o tema.

\section{Metodologia}

Para que seja possível compreender a necessidade de um espaço infantil para o amparo infantil na comunidade científica brasileira de Computação dentro dos eventos da SBC, é preciso conhecer, primeiramente, a opinião de pessoas interessadas por este tipo de serviço. Assim, foi realizado um levantamento de dados por meio de uma pesquisa exploratória de opinião do tipo survey research [Given 2008], para buscar a necessidade de tornar eventos da SBC inclusivos para cientistas por meio da oferta de um espaço que possa acolher suas crianças durante os eventos científicos organizados pela SBC.

Para execução da pesquisa de opinião, encaminhou-se um e-mail em dezembro de 2019 por meio da lista de e-mails mantida pela SBC $^{11}$ divulgando o questionário on-line ${ }^{12}$. As pessoas participantes desta lista que responderam ao questionário foram convidadas a refletir respondendo questões sobre: identificação, situação familiar e parentalidade, experiências prévias em eventos com recreação infantil e demandas de um espaço infantil.

O questionário foi dividido em 5 seções: (1) identificação - com duas questões: gênero e parentalidade ${ }^{13}$; (2) informações, com duas questões: número de filhas e filhos e idade das crianças; (3) espaço infantil / experiência prévia para respondentes sem crianças $^{14}$, com quatro questões; (4) espaço infantil / experiência prévia para respondentes

\footnotetext{
${ }^{10}$ Como o exemplo de 2016, quando uma mãe palestrante teve sua entrada barrada em estrutura da Campus Party Brasil por portar alimentação para a sua bebê - https://blogs.ne10.uol.com.br/mundobit/ 2016/01/28/organizacao-da-campus-party-brasil-proibe-entrada-de-alimentos-e-gera-revolta/

${ }^{11}$ Listas enviadas: sbc-1@sbc.org.br e meninasdigitais@googlegroups.com

12 bit.ly/EspacoKidsMDSBC

${ }^{13}$ Mãe, pai, responsável ou nenhuma das opções, mas quero participar da pesquisa

${ }^{14}$ Somente respondentes sem crianças tinha acesso a esta seção.
} 
com crianças ${ }^{15}$, com cinco questões; (5) espaço infantil / demandas, com seis questões.

Não se questionou sobre a categoria de associação de cada participante da pesquisa, o que pode ser considerada uma limitação para a análise da representatividade de cada categoria nos resultados. O questionário esteve disponível por 48 dias e foram obtidos 131 registros de respostas. A seção a seguir apresenta a análise e discussão dos resultados da pesquisa de forma qualitativa, considerando diferentes categorias de análise: gênero, experiência e demandas para um espaço infantil.

\section{Análise dos Resultados}

Inicialmente, é importante apresentar o panorama geral de respondentes, de acordo com seu gênero e tipo de parentesco com as crianças (Figura 1.a): 30 pessoas não possuem filhos e 101 declaram ser responsáveis por alguma criança (no papel de mãe, pai ou responsável (Figura 1.b).

É relevante observar que a maioria das respondentes (78) é de gênero feminino, representando $60 \%$ da amostra. As participantes no papel de mãe (60) representam 45,8\% da amostra geral e 75,6\% do total de participantes de gênero feminino. Do total de participantes da pesquisa, 38\% se identificam com o gênero masculino, 50 participantes, dos quais 39 (29,8 do total de participantes e $78 \%$ do total de gênero masculino) informaram que são pais. Por fim, 3 pessoas (2\%) preferiram não indicar sua identificação de gênero, destas 2 pessoas afirmaram ser responsáveis por criança(s).
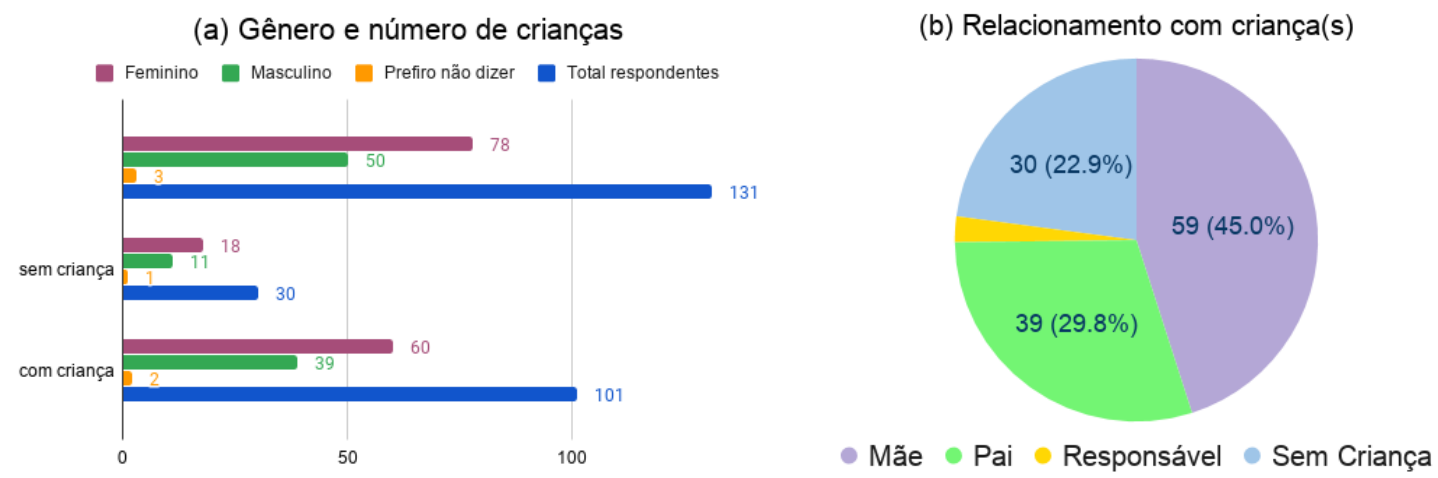

Figura 1. Perfil dos respondentes sobre (a) gênero e quantidade de crianças; (b) tipo de parentalidade

Segundo Jéssica Azevedo et al. (2019), em novembro de 2018 havia 6963 pessoas associadas à SBC sendo, 1509 do gênero feminino e 5390 do gênero masculino. Considerando esta distribuição e que há um intervalo de um ano entre os dados, podendo haver alterações nos dados de pessoas associadas neste período, uma hipótese possível seria considerar que o número de respondentes de gênero masculino fosse maior do que de gênero feminino. Entretanto, esta hipótese não foi confirmada. Ao contrário, a maioria de participantes da pesquisa se identificou como sendo de gênero feminino.

Embora 131 respostas representem, aproximadamente, 1,9\% das associações da SBC, segundo Azevedo et al. (2019), se considerarmos apenas a proporção de gênero feminino, 78 respondentes correspondem à 5,16\% das associações de pessoas de gênero feminino da SBC. Por outro lado, a participação de pessoas de gênero masculino foi bastante incipiente, sendo $0,92 \%$ considerando 5390 associações de gênero masculino. É

\footnotetext{
${ }^{15}$ Somente respondentes com crianças tinha acesso a esta seção.
} 
possível que estes dados representem um maior interesse na temática por parte das mulheres e mães cientistas por experenciarem uma divisão de responsabilidades desigual em gênero quanto ao cuidado de crianças.

Quanto aos dados referentes ao número de crianças, a partir das respostas das pessoas de gênero feminino é possível identificar que a maioria $60 \%(35 / 59)$ é mãe de uma criança, 30\% (18/59) é mãe de duas crianças e 10\% (6/59) é mãe de 3 ou mais crianças. Analisando as respostas de participantes de gênero masculino, 46\% (18/39) dos pais têm uma criança, 44\% (17/39) é pai de duas crianças e 10\% (4/39) filhos de três ou mais crianças.

Com relação à idade das crianças, há uma distribuição uniforme quanto à faixaetária, totalizando 39/101 crianças com idade de até três anos, 38/101 crianças de três a cinco anos, 35/101 crianças de seis a nove anos e 39/101 crianças acima de 9 anos.

A Tabela 2 traz um panorama geral dos resultados com relação à experiência de participação em conferências científicas com espaço infantil e uso de tal espaço (última coluna da tabela). É possível observar que a maioria das pessoas com criança(s), ainda não teve a experiência de participar de conferências científicas com espaço infantil. Nas colunas "sem experiência" estão incluídas também as respostas "não sei". Esta opção de resposta reflete uma situação na qual a pessoa participou de um evento, mas não se informou ou não foi informada sobre o serviço de espaço infantil.

Tabela 2. Panorama geral da experiência em eventos com espaço infantil

\begin{tabular}{|c|c|c|c|c|c|}
\cline { 2 - 6 } \multicolumn{1}{c|}{} & $\begin{array}{c}\text { sem criança } \\
\text { sem } \\
\text { experiência }\end{array}$ & $\begin{array}{c}\text { sem criança } \\
\text { com } \\
\text { experiência }\end{array}$ & $\begin{array}{c}\text { com criança } \\
\text { sem } \\
\text { experiência }\end{array}$ & $\begin{array}{c}\text { com criança } \\
\text { com } \\
\text { experiência }\end{array}$ & $\begin{array}{c}\text { fez uso } \\
\text { do espaço }\end{array}$ \\
\hline Feminino & 9 & 9 & 52 & 8 & 6 \\
\hline Masculino & 11 & - & 35 & 4 & 4 \\
\hline Prefere não dizer & 1 & - & 1 & 1 & - \\
\hline Total & 21 & 9 & 88 & 13 & 10 \\
\hline
\end{tabular}

Ao observar os dados da Tabela 2, identifica-se ainda que a mesma porcentagem (apenas 10\%) de pessoas de gênero feminino e de gênero masculino com criança(s), fizeram uso do espaço infantil. Duas pessoas de gênero feminino e uma pessoa de gênero não informado tiveram a experiência de estar em uma conferência com este tipo de infraestrutura, entretanto, não fizeram uso deste espaço. É importante destacar que 10 das 13 pessoas com crianças que já tiveram a oportunidade de usar o espaço infantil em um evento científico, utilizaram este espaço. Destas, todos os participantes do gênero masculino no papel de pai usaram o recurso, apenas duas mães não usaram e uma pessoa não respondeu sobre o uso. Apesar de serem poucos registros (13), estes dados são significativos, pois revelam que, quando há a disponibilidade do recurso e há informação sobre o mesmo, este recurso é utilizado pela comunidade científica.

A percepção das 9 pessoas participantes sem crianças sobre a participação em eventos que ofereceram espaço para acolher crianças é totalmente positiva, conforme ilustra a Figura 2. Uma participante (sem crianças) ressaltou: "Vi que os pais se sentiam mais convidados a participarem do evento e empolgados em apresentarem seus trabalhos, principalmente as mães.". Os resultados sobre as percepções de mães e pais sobre sua experiência no uso de espaço infantil em eventos científicos e também suas percepções sobre a experiência das crianças são motivadoras. A maioria das percepções é positiva para 4 mães ( 2 boa e 2 muito boa) e para todos os 4 pais ( 2 boa e 2 muito boa) 
que tiveram a experiência de uso de um espaço infantil em conferências. Apenas 2 mães tiveram percepções negativas sobre suas experiências e sobre as experiências das crianças no uso de espaço infantil no contexto de conferências científicas. Uma mãe relatou que a experiência foi ruim para ela e outra que foi muito ruim. E ambas classificaram como ruim a experiência para a criança.
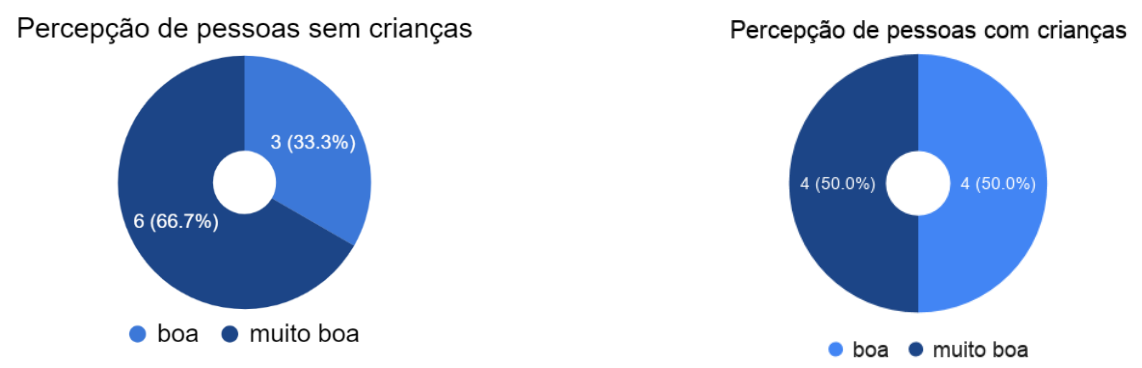

Figura 2. Percepção das pessoas sem e com crianças sobre eventos com espaço infantil

A maioria das pessoas participantes da pesquisa com criança(s) $(72,3 \%)$ afirmaram que já deixaram de participar de um evento científico por não ter como cuidar ou com quem deixar suas filhas e filhos durante os dias do evento científico, sinalizando uma necessidade clara de soluções para este tipo de situação e uma possível demanda por espaço infantil dentro da comunidade da SBC. Em consonância com os resultados anteriores, a maioria das pessoas participantes da pesquisa com criança(s) (89\%) sinalizou que gostaria de ter a opção de levar as crianças para um evento científico com espaço infantil. Desta maioria, $63 \%$ pagariam pelo serviço dependendo do valor, $23 \%$ utilizariam o serviço se este fosse oferecido gratuitamente e, $3 \%$ pagariam pelo serviço independente do preço. Apenas 7\% não gostariam de ter a opção de espaço infantil nos eventos da SBC e somente $4 \%$ responderam "talvez".

Também se questionou das pessoas participantes com criança(s) as razões pelas quais gostariam da inclusão das crianças nos eventos. A pergunta tinha opções de múltipla escolha como resposta, além de uma opção aberta. Obteve-se 92 respostas para esta questão das 101 mães, pais e responsáveis. A maioria (68\%) respondeu que a principal razão seria para estar mais tempo perto da criança. Em segundo lugar, $57 \%$ afirmam que não teriam condições de participar de um evento se não levassem a criança. Oferecer uma experiência diferente para a criança foi escolhida por $49 \%$ de participantes e $10 \%$ responderam já ter vivido a experiência, sendo esta muito positiva tanto para pessoas adultas quanto para a(s) criança(s). Duas outras razões foram indicadas na opção em aberto: "Possível aprendizado para a criança" (uma pessoa) e "Proporcionar a criança o entendimento do mundo profissional em que trabalho" (uma pessoa). Por estes dados, percebe-se que, além de uma necessidade para mais da metade das pessoas respondentes (57\%) participarem de um evento, elas também acreditam que a oferta de um espaço infantil auxiliaria no vínculo familiar. Tais dados corroboram com as proposições do relatório do Fórum da Internet do Brasil [Maciel et al. 2019].

$\mathrm{Na}$ seção de questões sobre a demanda de um espaço infantil, questionou-se também sobre o(s) momento(s) do evento em que este serviço deveria ser oferecido. A Figura 3 ilustra que $75 \%$ das pessoas respondentes gostariam que o espaço infantil atendesse as crianças durante as palestras, $73 \%$ durante as sessões técnicas e $63 \%$ durante os minicursos. É importante ressaltar que cada participante poderia selecionar mais de uma resposta para esta questão. As demais opções referentes aos momentos sociais e de 
recesso do evento (coffee break, almoço, jantar e coquetel) foram escolhidas por uma parcela menor de participantes. E, por fim, "todas as opções" foi escolhida por $20 \%$ de respondentes. Ou seja, a indicação foi maior para momentos de maior formalidade acadêmica e com maior necessidade de concentração da atenção nos eventos.

Quando o espaço kids deve estar disponível?

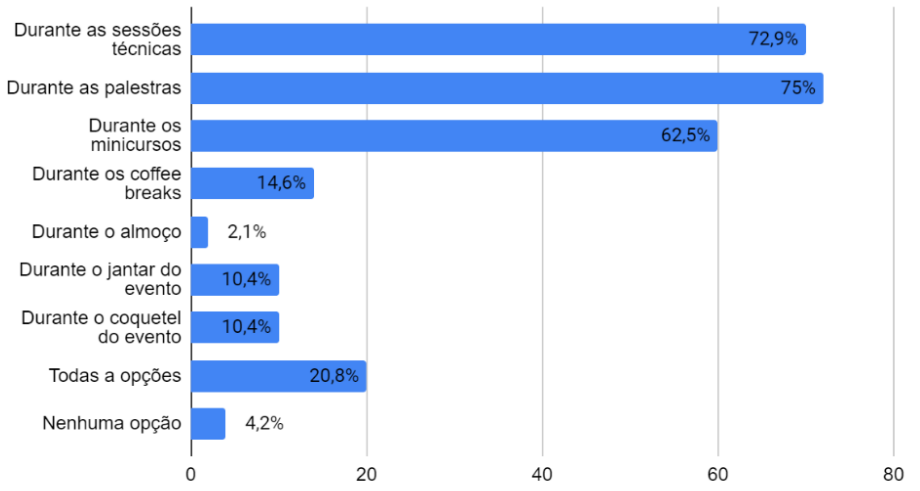

Figura 3. Momentos de oferta do espaço infantil

Com relação às atividades que o espaço poderia oferecer durante os eventos da SBC, o questionário apresentou oito opções, para múltipla escolha, além da opção de cada participante indicar outras demandas. As opções mais escolhidas foram: atividades lúdicas e artísticas como pintura, teatro, música (91\%), jogos analógicos (88\%) e contação de histórias $(86 \%)$. Outros serviços necessários a serem considerados no espaço infantil indicados pelas pessoas foram: alimentação para as crianças (54\%), espaço para a criança dormir (44\%) e espaço para amamentação (32\%). E por fim, o público consultado ainda sinalizou interesse na oferta de jogos digitais $(34,7 \%)$ e exibição de filmes e séries $(31,7 \%)$. As opções livres indicadas por uma pessoa cada foram: "banheiro", "atividades voltadas para o geoprocessamento" e "alimentação do tipo lanche (não almoço)".

Por fim, a última pergunta do questionário era um espaço aberto disponível para as pessoas participantes fazerem comentários relacionados ao tema. Foram coletadas opiniões positivas à oferta do serviço de acolhimento para crianças em eventos científicos, sinalizando diversos benefícios que reforçam os pontos discutidos anteriormente, como ilustram os exemplos das declarações a seguir ${ }^{16}$.

Declaração A: "Acho importante ter esse espaço, tanto para pais e mães que queiram comparecer a congressos (mas não podem por causa dos filhos) e até para incentivar crianças para a área de informática." (Mulher sem crianças)

Declaração B: "Precisamos de mais espaços que acolham as crianças, sejam em eventos científicos ou nas nossas Universidades/Faculdades. Parabéns pelo levantamento." (Pai de 1 criança)

Declaração C: "Todos os eventos acadêmicos deveriam incluir espaço infantil, mas não apenas ter um espaço reservado para crianças, pois elas devem circular livremente em todos os ambientes. Neste caso, as pessoas também precisam entender que a academia deve ser ocupada pela infância, o que requer saber lidar de forma gentil com choros e gritos naturais desta fase que todxs nós, adultos, já passamos um dia." (Mãe de 2 crianças) Declaração D: "Acho a ideia ótima. Durante os anos iniciais da minha filha, deixei de ir a eventos por não poder deixá-la. Agora que já está maior, seria ótimo levá-la aos eventos e poder mostrar um pouco mais sobre meu trabalho. Um espaço dedicado ao cuidado das crianças seria de grande ajuda." (Mãe de 1 criança)

\footnotetext{
16 Transcritas na íntegra, preservando a linguagem utilizada por participantes da pesquisa.
} 
Por outro lado, houve algumas posições contrárias a este tipo de recurso em eventos por mães e por pessoas de gênero masculino sem crianças. As declarações a seguir trazem na íntegra essas respostas ${ }^{16}$.

\begin{abstract}
Declaração E: "Não acho uma ideia necessária." (Mãe de 3 crianças) Declaração F: "Acho conturbado levar crianças para os eventos científicos." (Mãe de 1 criança)

Declaração G: "Na minha opinião não foi uma experiência prazerosa, pois o aglomerado de crianças causou muito barulho e correria, e atrapalhou as seções e workshops que estavam acontecendo." (Homem sem crianças)

Declaração H: "Por favor, levem a resposta com 'a grain of salt' dado que não tenho filhos ainda, mas não apoio a existência de um espaço kids em eventos da SBC. Os eventos são um espaço importante para troca de ideias e que exigem concentração da parte dos participantes; levar crianças para os eventos fariam que os pais e mães acabassem com a atenção dividida e, certamente, as oportunidades que surgem pela interação entre participantes (durante e após os horários de trabalho do evento) seriam perdidas." (Homem sem crianças)
\end{abstract}

\title{
5. Considerações finais
}

Considerando os dados analisados na pesquisa qualitativa exploratória deste artigo, podese perceber uma tendência predominantemente positiva para a inclusão das crianças nos eventos científicos da SBC, com espaços de recreação e de cuidado compartilhado para que mães, pais e responsáveis tenham a possibilidade de participar destes eventos sem a necessidade de se afastar de filhas e filhos, tendo em vista que a maioria das pessoas respondentes possui uma criança com idade entre 1 e 5 anos.

Acredita-se que os dados da presente pesquisa revelaram uma necessidade por tempos escondida sobre o trabalho de cuidar e educar crianças. O trabalho científico, dentre os quais está a atividade de publicação, colaboração e participação em eventos nacionais e internacionais, afeta profissionais que são mães, pais ou responsáveis e têm pouco ou nenhum apoio estrutural no cuidado das crianças na ocasião destes eventos. Entre as pessoas participantes desta pesquisa, 72,3\% disseram que já deixaram de participar de um evento científico por não ter como cuidar ou com quem deixar sua(s) filha(s) e seu(s) filho(s) durante o período do evento. Se a participação em eventos da área da Computação por mães pesquisadoras e pais pesquisadores é reduzida, então as suas redes de contatos e suas oportunidades de trabalho e colaboração podem ser restringidas, afetando negativamente suas carreiras e, consequentemente, a busca pela equidade de gênero, tanto na parentalidade, quanto na comunidade científica de Computação.

A questão trazida neste artigo sobre a necessidade de oferecer espaço infantil em eventos científicos da SBC já é uma solução adotada em outras áreas do conhecimento no Brasil, além de ser uma solução utilizada em outros países através da criação de editais para financiamento de despesas relacionadas ao cuidado de crianças, que incluam passagem aérea para a criança viajar junto ou para uma pessoa acompanhante que cuide da criança. Outras soluções alternativas que vão ao encontro da demanda pelo cuidado de crianças durante eventos científicos são apoio financeiro para o pagamento de pessoas cuidadoras infantis (day care vouchers) - já praticado em alguns eventos de empresas de tecnologia no país - e o estabelecimento e creches gratuitas próximas ou no próprio local de trabalho das pessoas cientistas, como as creches universitárias, por exemplo. Todavia, a parentalidade responsável ainda não é uma realidade em eventos da Computação no Brasil, motivo pelo qual o estudo ora apresentado discute e propõe essas possibilidades. 
Como próximos passos espera-se organizar uma proposta de espaço kids para apresentar ao comitê gestor do Programa Meninas Digitais e à organização dos eventos apoiados pela SBC para servir de apoio na busca de patrocínios para implementação de tais espaços. Outras ações futuras possíveis, que surgiram em decorrência da crise global de saúde atual (pandemia da Covid-19), pode-se repetir parte da pesquisa convidando as pessoas a responderem como foi a experiência de participar de eventos on-line com crianças em situação de isolamento social e investigar iniciativas para a realização de atividades no formato on-line para as crianças que estão junto aos pais durante o evento.

\section{Agradecimentos}

Essa pesquisa contou com o apoio do Conselho Nacional de Desenvolvimento Científico e Tecnológico - CNPq.

\section{Referências}

Azevedo, J. et al. (2019). Análise de perfil da Sociedade Brasileira de Computação: Um recorte de gênero, In: Proceedings of Congresso da Mulher Latino-americana em Computação (LAWCC), CLEI 2019, Panamá.

Calisi, R. et al. (2018) Opinion: How to tackle the childcare-conference conundrum. PNAS, vol. 115, n. 12, 2845-2849 https://doi.org/10.1073/pnas.1803153115

CNPQ (2017) Censo Pesquisadores por liderança, sexo e idade 2017. Disponível em: http://lattes.cnpq.br/web/dgp/por-lideranca-sexo-e-idade

Elsevier (2017). Gender in the Global Research Landscape: Analysis of Research Performance Through a Gender Lens Across 20 Years, 12 Geographies, and 27 Subject Ares. Elsevier, 2017.

Given, L. M. (2008). The SAGE encyclopedia of qualitative research methods. Thousand Oaks: Sage Publications, 1014 p.

Langin, K. (2018) Are conferences providing enough child care support? We decided to find out. Science. doi:10.1126/science.caredit.aaw3741

Machado, L. S. et al. (2019). Parent in science: the impact of parenthood on the scientific career in Brazil. In: Proceedings of 2nd International Workshop on Gender Equality in Software Engineering (GE), IEEE/ACM, 2019.

Maciel, C. et al. (org.). A internet como agente para diminuir a diferença de gênero na área de TIC. In: FÓRUM DA INTERNET NO BRASIL, 9., 2019. Manaus.

Relatório [...]. Manaus: Comitê Gestor da Internet no Brasil, 2019. Disponível em: https://minhaagenda.nic.br/files/apresentacao/arquivo/738/A_Internet_como_Agente _para_Diminuir_a_Diferenca_de_Genero_na_Area_de_TIC\%20.pdf.

Maciel, C. et al. (2018). Digital girls program: disseminating computer science to girls in Brazil, In: Proceedings of the 1st International Workshop on Gender Equality in Software Engineering (GE '18). Association for Computing Machinery, New York, NY, USA, 29-32. https://doi.org/10.1145/3195570.3195574

Parent in Science (2020). "Sobre o Parent in Science - 2020" Disponível em: http://www.parentinscience.com.br 